American Journal of Animal and Veterinary Sciences, 2012, 7 (4), 149-158

ISSN: $1557-4555$

(C) 2012 J.E. Larson et al., This open access article is distributed under a Creative Commons Attribution

(CC-BY) 3.0 license

doi:10.3844/ajavssp.2012.149.158 Published Online 7 (4) 2012 (http://www.thescipub.com/ajavs.toc)

\title{
Porcine Respiratory and Reproductive Syndrome Virus Vaccinology: A Review for Commercial Vaccines
}

\author{
Papatsiros, V.G. \\ Department of Medicine, Faculty of Veterinary Medicine, \\ University of Thessaly, Greece, 43100, Karditsa, Greece
}

Received 2012-05-31, Revised 2012-06-18; Accepted 2012-11-05

\begin{abstract}
Porcine Reproductive and Respiratory Syndrome (PRRS) since its appearance in Europe in the early 1990's has resulted in tremendous economic losses. Under field conditions vaccination is one of the most efficient strategies for the prevention and control of PRRS. The aim of this study is to perform the PRRSV vaccinology regarding current status of commercial vaccines in Europe. There are two types of PRRSV commercial available vaccines in Europe: Killed Virus (KV) or inactivated vaccines and Modified-Live Virus (MLV) or attenuated vaccines. EU KV commercial vaccines provide limited efficacy due to the weak stimulation of the immune system and no effective induction of neutralizing antibodies. However, KV vaccines can induce a strong Cell Mediated Immune (CMI) response. One the other hand, commercial EU MLV vaccines provide effective strain-specific protection, only partial protection against genetically heterologous PRRSV and elicit relatively late humoral and CMI responses which lead to delayed protection. In Europe, the KV vaccination prove to reduce the negative effects of PRRSV in breeding herds, improving their reproductive performance, e.g., increase of farrowing rate and number of live or weaned pigs, reduction of premature farrowing rate, abortion rate and number of mummified and stillborn piglets. The use of commercial MLV vaccines in PRRSV-infected breeding herds leads to improvement of: (a) reproductive performance e.g., reduction of the abortion and return to oestrus rate and increase of the farrowing rate and number of weaners, (b) the viraemic status, morbidity and mortality rate of piglets and (c) the growth performance of vaccinated pigs. In conclusion, nowadays the use of MLV or KV vaccines in Europe is the most economical tool to control the economic losses of PRRSV infection. However, the development of more efficacious PRRSV vaccines is the significant future goal for PRRSV vaccinology.
\end{abstract}

Key words: Vaccine, Inactivated, Killed Virus (KV), Cell Mediated Immune (CMI), Porcine Reproductive and Respiratory Syndrome (PRRS), Modified-Live Virus (MLV)

\section{INTRODUCTION}

Porcine Reproductive and Respiratory Syndrome (PRRS) since its first report in the late 1980s in Western Europe (Wensvoort et al., 1991) and North America (Keffaber, 1989) has caused a significant economic impact on the global swine industry (Neumann et al., 2005). The aetiological agent of PRRS is an RNA virus (PRRSV) of the order Nidovirales, family Arteriviridae, genus Arterivirus. PRRSV strains are divided into two genotypes, the Type I or European (EU) type and Type II or North American (NA) type. Type I, with the prototype Lelystad Virus (LV), has a predominant spread on Europe, while Type II with the prototype ATCC VR2332, represents strains isolated on the American continent, as well as in Asia (Wensvoort et al., 1991; Meulenberg et al., 1993; Murtaugh et al., 1995; Nelsen et al., 1999; Mateu et al., 2006). According to the recent reports for PRRSV classification, Type I is divided into 3 subtypes: a pan European subtype 1 and East European subtypes 2 (Stadejek et al., 2002; 2006; 2008; Toplak et al., 2012). Among them, the subtype 1 
was further divided into 12 different clades (Stadejek et al., 2008; Shi et al., 2010a). For Type II, 9 well-defined lineages have been described (Shi et al., 2010a; 2010b). Both NA (Kapur et al., 1996; Goldberg et al., 2000; Key et al., 2001) and EU (Indik et al., 2000; Oleksiewicz et al., 2000; Forsberg et al., 2002) genotype strains are antigenically and genetically highly distinguishable. Nowadays, a coexistence of the two genotypes has been reported in Europe, North America and Asia, complicating the diagnosis, prevention and control of disease (Dewey et al., 2000; Ropp et al., 2004; Fang et al., 2007; Balka et al., 2008; Amonsin et al., 2009).

PRRSV causes reproductive failure in breeding herd and respiratory disease in growing/finishing pigs (Zimmerman et al., 2006). Zimmerman While the severity of the disease can be variable depending on the particular strain of PRRSV that infects the herd, all strains are capable of causing reproductive failure in the breeding herd e.g., increased premature farrowing and late term abortion rate, poor farrowing rate, mummified fetuses and stillborn piglets as well as respiratory disease, characterized by elevated mortality and decreased growth performance in piglets and growing/finishing pigs (Chung et al., 1997; Cho and Dee, 2006).

Vaccination belongs to the most predominant strategies for the prevention and control of economic losses caused by PRRSV. The purpose of this present study is to perform the PRRSV vaccinology regarding current status of commercial PRRS vaccines in European market.

\subsection{PRRSV Vaccinology in Europe}

The vaccination is considered a crucial measure for the prevention and control of PRRS infection. It is also the most economic strategy for all sizes of pig farms i.e., small, medium and large) compared with other control strategies. There are two types of PRRSV commercial available vaccines in Europe: Killed Virus (KV) or inactivated vaccines and Modified-Live Virus (MLV) or attenuated vaccines.

\subsection{KV (Inactivated) Vaccines}

Inactivated PRRSV vaccines are used for the immunization of breeding herd. Information about vaccination schedule of available commercial inactivated PRRSV vaccines in Europe are summarized in Table 1.

Their main advantage is safety, as the vaccine virus cannot transmit to other pigs and cannot revert to virulence. Field studies reported that the KV vaccines did not induce reproductive failure in vaccinated sows and gilts (Plana-Duran et al., 1997; Joisel et al., 2001;
Papatsiros et al., 2006). However, their efficacy has been frequently questioned. The capacity of $\mathrm{KV}$ vaccines induce a protective immunity against challenge with wildtype virus has been questioned. Kim et al. (2011) reported that the KV vaccination did not elicit detectable VirusNeutralizing (VN) antibodies and provide weak memory responses with sequential challenge (Kim et al., 2011). It also barely elicits strong Cell Mediated Immune (CMI) response as determined by lymphocyte proliferation and IFN $\gamma$ production in recall response (Bassaganya-Riera et al., 2004; Piras et al., 2005). The KV vaccination of PRRSVpositive pigs results in an increase of $\mathrm{VN}$ antibodies and CMI responses, 2 weeks after the revaccination, providing significant protection (Kim et al., 2011; Bassaganya-Riera et al., 2004). Studies with commercial $\mathrm{KV}$ vaccines indicated that the vaccination did not induce VN antibodies and did not sufficiently protect against viremia or prevent from the clinical signs of PRRS (Nilubol et al., 2004; Scortti et al., 2007; Zuckermann et al., 2007). However, the long term use of a commercial KV vaccine under field conditions resulted in a remarkable improvement of reproductive performance in breeding herd, without VN antibodies induction (Papatsiros et al., 2006). On the contrary, studies with experimental KV vaccines reported induction of $\mathrm{VN}$ antibodies and decrease of the viremia duration (Misinzo et al., 2006; Vanhee et al., 2009).

The first KV vaccine in European market was Cyblue ${ }^{\circledR}$ (Lab. Ford Dodge). Studies with this vaccine had shown conflicting results about its efficacy, such as beneficial effects on reproductive performance of vaccinated sows (Plana-Duran et al., 1997) or weakness to prevent viremia nor to avoid transplacental infection in vaccinated gilts exposed to PRRSV at the time of conception (Prieto et al., 1997) or no effect on reproductive performance of vaccinated females in comparison to unvaccinated ones (Scortti et al., 2007). However, nowadays, there are four commercial available $\mathrm{KV}$ vaccines in Europe (Table 1). Field studies with some of these nowadays commercial available KV vaccines reported that the vaccination has beneficial effects on reproductive performance and litter characteristics of vaccinated sows in PRRSV-infected farms, where PRRSV circulate among breeding animals (Table 2). In particularly, the KV vaccination proved to reduce the negative effects of the PRRSV on the breeding herd with persistent PRRSV infection and high seroprevalence, improving their reproductive performance, e.g., increase of farrowing rate, number of live or weaned pigs and reduction of premature farrowing rate, abortion rate and number mummified and 
Papatsiros, V.G. / American Journal of Animal and Veterinary Sciences 7 (4) (2012) 149-158

stillborn piglets (Joisel et al., 2001; Papatsiros et al., 2006; Papatsiros, 2012a). The beneficial effects of vaccination with $\mathrm{KV}$ vaccines can reduce the culling rate due to reproductive failure, resulting in a significant improvement of longevity and number of non-productive days in the vaccinated breeding herd (Papatsiros, 2012a). However, the KV vaccination in naive animals, fails to prevent reproductive losses and congenital infection in foetuses (Scortti et al., 2007).

The use of inactivated PRRSV vaccine should be administered on a regular basis for obtaining the maximum beneficial effect, as it has been observed that the higher the degree of immunization of sows, the better the improvement of their health status and reproductive performance (Papatsiros, 2012b). In a field study with long term use of a commercial vaccine indicated that while the increase of the number of booster vaccinations improved respectively several performance parameters, no further improvement of the level of immunity as measured by IPMA were noticed (Papatsiros et al., 2006). In general, the KV vaccination is proposed to be applied on a regular basis in breeding herd of endemic PRRSVinfected farms, in order to obtain a stabilization of their immunity, preventing the losses due to annually PRRS outbreaks (Papatsiros, 2012b).

Except of the vaccination of females, the vaccination of boars with $\mathrm{KV}$ vaccines is considered to be safe. Field study with long term use of commercial $\mathrm{KV}$ vaccine shown that the vaccination is absolutely safe and no negative effects on semen quality were noticed (Papatsiros et al., 2011).

\subsection{Modified (or Attenuated) Live Vaccines (MLV)}

Commercial MLV vaccines elicit relatively weak humoral and CMI responses. PRRSV-specific antibodies appear approximately 2 weeksand peak around 4 weeks after vaccination, which have no neutralizing activity and they do confer some clinical protection (Darwich et al., 2010). PRRSV-specific VN antibodies appear approximately 4 weeks after vaccination and have relatively low titers throughout the course of immunization (Darwich et al., 2010). PRRSV-specific CMI response appears approximately 2-4 weeks after vaccination as determined by lymphocyte blastogenesis and interferon $\gamma$ (IFN $\gamma$ ) production in recall reaction (Meier et al., 2003; Bassaganya-Riera et al., 2004).

Table 1. Commercial available PRRSV vaccines in Europe

\begin{tabular}{|c|c|c|c|c|}
\hline Current name & Type & Virus strain & Manufacturer & Vaccination schedule \\
\hline PROGRESSIS $^{\circledR}$ & Inactivated & P120 KV strain $>2.5 \log 10$ IF units & Merial animal health Ltd & $\begin{array}{l}\text { Primary vaccination (gilts and } \\
\text { sows): twice (im), 3-4 wk interval } \\
\text { at least } 3 \text { wk prior to mating } \\
\text { Revaccination (booster) one dose } \\
\text { (im) at } 60-70 d \text { of each gestation }\end{array}$ \\
\hline INGELVAC® PRRS KV & Inactivated & P120 KV strain $>2.5 \log 10$ IF units & Boehringer Ingelheim Ltd & $\begin{array}{l}\text { Breeding stock Primary vaccination } \\
\text { (gilts and sows): twice im, } 3-4 \mathrm{wk} \\
\text { interval, at least } 3 \text { wk prior to } \\
\text { mating Revaccination (booster): } \\
\text { one injection im at } 60-70 \mathrm{~d} \\
\text { of each gestation }\end{array}$ \\
\hline SUIVAC $^{\circledR}$ PRRS-Ine & Inactivated & $\begin{array}{l}\text { VD-E1 KV strain }\left(10^{4.8} \text { up to } 10^{6.3}\right. \\
\text { CCID }_{50} \text { prior to inactivation) } \\
\text { VD-E2 KV strain }\left(10^{3.8} \text { up to } 10^{5.3}\right. \\
\text { CCID } 50 \text { prior to inactivation }) \\
\text { VD-A1 KV strain }\left(10^{4.8} \text { up to } 10^{6.3}\right. \\
\text { CCID }_{50} \text { prior to inactivation) }\end{array}$ & Dyntec spol. sr.o. & $\begin{array}{l}\text { Breeding stock Primary vaccination } \\
\text { (gilts and sows): twice (im), } 3-4 \mathrm{wk} \\
\text { interval, at least } 3 \mathrm{wk} \text { prior to } \\
\text { mating } \\
\text { Piglets three doses (im) at } 3-4 \mathrm{wk}\end{array}$ \\
\hline SUIPRAVAC® PRRS & Inactivated & $5710 \mathrm{KV}$ strain & HIPRA & $\begin{array}{l}\text { Breeding stock Primary } \\
\text { vaccination: entering the farm / } \\
\text { Sows (pregnancy or lactation): } \\
\text { Twice (im), at 3-4 wk interval } \\
\text { Revaccination (booster }\end{array}$ \\
\hline AMERVAC® PRRS & MLV & Live strain VP046 BIS $\geq 10^{3.5}$ TCID $_{50}$ & HIPRA & Piglets: one dose (im) at age of $4-5 \mathrm{wk}$ \\
\hline PYRSVAC-183® & MLV & Live strain ALL- $183 \geq 10^{5.0}$ TCID $_{50}$ & SYVA laboratories & Piglets: one dose (im) over \\
\hline PORCILIS® PRRS & MLV & $\begin{array}{l}\text { Live strain DV } 10^{4.0} \mathrm{TCID}_{50}-10^{6.3} \\
\text { TCID }_{50}\end{array}$ & MSD animal health & $\begin{array}{l}\text { Breeding stock Primary vaccination: } \\
\text { one Revaccination (booster6 d of } \\
\text { lactation or at random } \\
\text { Piglets one dose (im or id), from } \\
\text { vaccinated at least } 2-4 \mathrm{wk}\end{array}$ \\
\hline
\end{tabular}


Papatsiros, V.G. / American Journal of Animal and Veterinary Sciences 7 (4) (2012) 149-158

The frequency of PRRSV-specific $\mathrm{T}$ cells producing IFN $\gamma$ increases gradually with age, reaching a peak at approximately 32 weeks of vaccination (Meier et al., 2003). Studies indicated that MLV-vaccinated pigs could not develop systemic anamnestic antibody and CMI responses after the challenge with homologous strains to the MLV vaccine virus, while they could develop anamnestic immune responses to the genetically heterologous strains (Martelli et al., 2007; 2009). However, the aforementioned findings are yet unknown, but it did not seem to affect the protective efficacy of the MLV vaccine (Martelli et al., 2007; 2009).

The vaccination schedule of available commercial MLV vaccines in Europe is summarized in Table 1. MLV vaccines are used for the prevention and control of PRRS infection both in breeding stock and young piglets, as is shown in Table 2. Studies with the use of commercial MLV vaccines in PRRSV-infected breeding herds reported beneficial effects on their health and performance, reducing the abortion and return to estrus rate and increasing farrowing rate and number of weaners (Alexopoulos et al., 2005; Pejsak and Markowska-Daniel, 2006). In addition, MLV vaccination of gilts protect them from viremia and reduce numbers of pre- and post-natal death and congenitally infected piglets (Scortti et al., 2006), while born piglets from vaccinated gilts can have higher body weight and survival rate at weaning than those derived from nonvaccinated gilts (Rowland, 2010). Recent evidences based on personal experience and field observations in endemic PRRSV-infected farms suffering by significant reproductive failure, the MLV vaccination of breeding stock can improve; (a) the reproductive performance, (b) the viraemic status of piglets, (c) the morbidity and mortality of piglets, (d) the growth performance of piglets (Papatsiros, 2012b).

Table 2. Literature data about the trials with commercial available PRRSV vaccines in Europe

\begin{tabular}{|c|c|c|}
\hline Type & Vaccination schedule & Results \\
\hline Inactivated & $\begin{array}{l}\text { Gilts/sows: primary vaccination (im), twice } \\
\text { at 3-4 wk apart, except those being } 1 \text { wk } \\
\text { prior to } 2 \text { wk post-service (the skipped } \\
\text { Booster vaccination: } 55-60 \mathrm{~d} \text { of gestation }\end{array}$ & $\begin{array}{l}\text { Improvement of reproductive performance and litter characteristics (e.g, } \\
\text { reduction of premature farrowing and abortion rate, increase of farrowing } \\
\text { rate, increase of live born and weaned piglets and decrease of stillborn, } \\
\text { mummified, weak and splay-legged piglets per litter) } \\
\text { The higher the degree immunization of a sow, the better the improvement of her } \\
\text { reproductive parameters } \\
\text { Reduction of culling rate due to reproductive failure }\end{array}$ \\
\hline Inactivated & Gilts (180 d of age): (im), twice at $3 \mathrm{wk}$ i & No detectable specific IFN- $\gamma$ response or protective immunity \\
\hline Inactivated & Piglets: (im) at weaninmg age & $\begin{array}{l}\text { Induction of a strong CMI response (significant specific IFN } \gamma+\mathrm{T} \text {-cell } \\
\text { response soon after vaccination) }\end{array}$ \\
\hline Inactivated & Piglets: (im) at mean age of 24 days & No induction of specific IFN- $\gamma$ response $60 \mathrm{~d}$ after vaccination \\
\hline MLV & Piglets: (im), twice, 21 and $42 \mathrm{~d}$ of age & $\begin{array}{l}\text { Elicited modest titre of neutralizing antibodies } \\
\text { Protection against homologous strain } \\
\text { Reduction of post-challenge viremia and completely blocking of PRRSV } \\
\text { dissemination to peripheral tissues }\end{array}$ \\
\hline MLV & Gilts: $90 \mathrm{~d}$ of gestation (intranasal) & $\begin{array}{l}\text { No clinical symptoms of general or reproductive performance } \\
\text { Vaccine strains can replicate in gilts and cross the placental barrier } \\
\text { No detrimental effects on the litters and congenitally infected pigs } \\
\text { Lack of transmission to non-infected piglets during lactation }\end{array}$ \\
\hline MLV & Gilts: $90 \mathrm{~d}$ of gestation (intranasal) & $\begin{array}{l}\text { No clinical symptoms of general or reproductive performance } \\
\text { Vaccine strains can replicate in gilts and cross the placental barrier } \\
\text { No detrimental effects on the litters and congenitally infected pigs } \\
\text { Lack of transmission to non-infected piglets during lactation }\end{array}$ \\
\hline MLV & $\begin{array}{l}\text { Gilts (5,5 months of age): (im), twice } \\
\text { at } 3 \text { wk apart }\end{array}$ & $\begin{array}{l}\text { Establishing of protective immunity } \\
\text { Protection is not based on humoral but rather on CMI }\end{array}$ \\
\hline MLV & $\begin{array}{l}\text { Sows: (im) every } 6 \text { months } \\
\text { Piglets: (im) at } 40 \mathrm{~d} \text { of age }\end{array}$ & $\begin{array}{l}\text { Protection up to } 108 \mathrm{~d} \text { of age } \\
\text { The high levels of sequence divergence between the vaccine and Polish } \\
\text { Field strains may reduce vaccine efficacy }\end{array}$ \\
\hline MLV & Piglets: (im or id) at 5 wk of age & $\begin{array}{l}\text { No effect of clinical protection by the route of administration } \\
\text { Partial clinical protection to a heterologous field strain } \\
\text { Efficient CMI response } \\
\text { Id route induce efficiently protection against a heterologous strain }\end{array}$ \\
\hline MLV & Piglets: (im or id) at $3 \mathrm{wk}$ of age & Partial cross-protection against closely related virulent strain \\
\hline MLV & Piglets: (im) at 4 wk of age & $\begin{array}{l}\text { Genetic diversity among European PRRSV field isolates may affect the } \\
\text { efficacy of the current European-type vaccines }\end{array}$ \\
\hline MLV & $\begin{array}{l}\text { Gilts: (im) at } 180 \mathrm{~d} \text { of age } \\
\text { Sows: (im) at } 10 \mathrm{~d} \text { post-partum }\end{array}$ & $\begin{array}{l}\text { Improvement of health status and reproductive performance of gilts/sows } \\
\text { and their litters (e.g., reduction of premature farrowing rate and the } \\
\text { number of dead and mummified born piglets, increase of farrowing rate } \\
\text { and the number of piglets born alive or weaned per litter) }\end{array}$ \\
\hline MLV & Piglets: (im) at 5 wk of age & $\begin{array}{l}\text { Reduction of grower's mortality } \\
\text { Improvement of average daily gain and feed conversion ratio }\end{array}$ \\
\hline
\end{tabular}


According to several studies, the use MLV commercial vaccines has beneficial effects on clinical disease occurrence and severity, the duration of viremia and virus shedding (Stadejek et al., 2005; Alvarez et al., 2006; Scortti et al., 2006; Martelli et al., 2007; Kimman et al., 2009). MLV vaccination can induce VN antibodies and protect against viremia, virus replication in lungs and virus induced respiratory and reproductive disorders (Labarque et al., 2003; Scortti et al., 2007; Zuckermann et al., 2007). In particular, the use of MLV commercial vaccines in piglets results in reduction of viremia, severity of respiratory clinical signs and improvement of their growth performance (Cano et al., 2007a; 2007b; Kritas et al., 2007). In co-infected farms by both PRRSV and PCV2, the MLV vaccination of piglets (at roughly 5 weeks old) improves their growth performance in vaccinated pigs (Kritas et al., 2007).

On the other hand, some studies have raised concerns about the efficacy of MLV vaccines. The protective immune response induced by current commercial MLV vaccines is influenced by genetic diversity, as these vaccines do not always sufficiently protect (or only partially) against re-infection and transplacental infections caused by heterologous PRRSV strains (Stadejek et al., 2005; Scortti et al., 2006; Prieto et al., 2008; Kimman et al., 2009). However, a recently study reported that vaccination of piglets at 5 weeks of age with a commercial MLV vaccine induced a partial clinical protection, associated with an efficient CMI response, when the above vaccinated pigs were exposed to a heterologous field strain (Martelli et al., 2009). It is possible that farmers using an MLV vaccine for the first time may experience a decrease in the herd productivity. Studies with MLV vaccinations in breeding stock reported outbreaks of acute PRRS-like clinical signs, associated with increased late term abortions, increased numbers of stillborns and mummified piglets, as well as decreased numbers of live born and weaned piglets (Botner et al., 1997; Dewey et al., 1999). Moreover, Zuckermann et al. (2007) reported delayed protection after MLV vaccination.

However, the use of MLV vaccines is remaining questionable. The major concern of MLV vaccines is the safety and mainly the possibility of the reversion of the vaccine virus to virulence due to genetic mutations of the vaccine virus and/or recombination with field virulent PRRSV strains (Murtaugh et al., 2010). Experimental and field studies reported that MLV strains can cause viremia, revert to virulence and spread transplacentally and horizontally not only within the vaccinated herds (transmission and detection in non-vaccinated pigs), but also to neighbouring non-vaccinated herds (Botner et al., 1997; Beilage et al., 2009; Kimman et al., 2009). The revert-to-virulent MLV vaccine can potentially cross placenta during late terms of gestation, causing increased number of mummified and stillborn piglets (Rowland, 2010). Piglets born to these MLV-infected sows can become carriers of PRRSV, shedding the MLV vaccine virus to other naive pigs (Rowland, 2010). Moreover, MLV vaccine can cause clinical respiratory signs and affect negative the growth performance of vaccinated piglets (Rowland, 2010). These vaccinated piglets can develop viremia, transmitting the MLV vaccine virus to other naive animals for a period of at least 4 weeks (Thanawongnuwech and Suradhat, 2010). Hence, it is possible that farmers using an MLV vaccine for the first time may experience decreased herd productivity, characterized for example by increased late term abortions or increased numbers of stillborns and mummified piglets (Botner et al., 1997; Dewey et al., 1999). An additional concern according to recently studies is that the MLV vaccination might interfere with the protective has efficacy of Mycoplasma hyopneumoniae vaccines (Thacker et al., 2000; Drexler et al., 2010; Roitha et al., 2011).

Both KV and MLV commercial EU vaccines are not able to protect completely against PRRSV infection. However, these vaccines have some beneficial effects on prevention and control of PRRS under field conditions, as shown in Table 2. According to Dotti et al. (2011) distinct patterns of immune response to a field PRRSV strain can be recognized in PRRS-vaccinated and naive pigs, which probably underlies fundamental differences in the development and differentiation of PRRSVspecific immune effector cells.

Commercial EU MLV vaccines provide effective genotype/strain-specific protection, only partial protection against genetically heterologous PRRSV and elicit relatively late humoral and CMI responses which lead to delayed protection (Scortti et al., 2006; Prieto et al., 2008; Martelli et al., 2009). However, the MLV vaccine virus has a potential risk to revert to virulence and cause clinical disease (Murtaugh et al., 2010). On the other hand, EU KV vaccines provide limited efficacy due to the weak stimulation of the immune system and no effective induction of $\mathrm{VN}$ antibodies, which might play a significant role in protection against either homologous or heterologous PRRSV. However, KV vaccines can induce a strong CMI response, which may associate with protection when are administered to the PRRSV-infected 
Papatsiros, V.G. / American Journal of Animal and Veterinary Sciences 7 (4) (2012) 149-158

pigs (Scortti et al., 2007; Zuckermann et al., 2007). In a recent study the effects of PRRSV vaccination, using combination of $\mathrm{KV}$ and a MLV vaccine was investigated by Gimeno et al. (2010). Initially piglets at six weeks of age were vaccinated with a EU MLV vaccine and three months later revaccinated with a commercial EU KV vaccine (once or twice) or with a EU MLV vaccine. At 6.5 months of age, all pigs were intranasal challenged with a Lelystad-like PRRSV strain. The results of this study indicated no differences in the humoral response but the revaccination with the KV vaccine had equal or better effect than the use of a repeated MLV vaccination in terms of maintaining the PRRSV-specific IFN- $\gamma$ response. These findings suggest that further studies are needed to carry out in order to evaluate and reclaim the advantages both of MLV and KV available vaccines.

The disadvantage of current commercially PRRSV (inactivated and MLV) vaccines to provide efficient or complete protection against PRRSV infection due to genetic diversity among European PRRSV field isolates and the limited cross-reactivity between strains of commercial vaccines and challenge strains (wild-virus strains) (Labarque et al., 2004). A significant genetically and antigenically diversity are noticed between mainly among EU PRRSV strains, but also different strains are isolated within the same area or the same farm (Labarque et al., 2004; Indik et al., 2000; Shi et al., 2010b; Toplak et al., 2012). This is probably caused by the introduction of a new strain into a single herd due to the introduction of replacement animals or semen rather than by local evolution, because different PRRSV strains are also isolated at the same time. Hence, the high heterogeneity among PRRSV strains is likely to be the main obstacle to effective control of PRRSV infection using current commercial vaccines (MLV and KV), since the immunity induced by one strain may be only partial against a different strain, even within the same genotype (Mateu and Diaz, 2008; Kimman et al., 2009). However, vaccine efficacy may be associated with an efficient CMI and it is not only related with its immunological properties, but also with the characteristics of the challenging strain to trigger an immune response (Martelli et al., 2009). Therefore, the ability of each strain to induce a strong CMI response is more important than the genetic similarity between the vaccine strain and the field strains for inducing clinical protection (Mateu and Diaz, 2008). The complexity of the immune response to PRRSV and the ability of the virus to escape or modulate the host's immune system make it difficult to develop an effective vaccine for control and eradication of PRRS.

\section{CONCLUSION}

In vaccinations are remained economical and effective control strategies for PRRS. The current use of MLV or KV vaccines in Europe is managing to moderate the economic losses due to PRRSV outbreaks. However, the major obstacle for the development of an ideal PRRSV vaccine is the lack of complete knowledge on several aspects of pathogenesis and immunity of PRRSV. The development of more efficacious PRRSV vaccines remains an important goal for the swine industry worldwide.

\section{REFERENCES}

Alexopoulos, C., S.K. Kritas, C.S. Kyriakis, E. Tzika and S.C. Kyriakis, 2005. Sow performance in an endemically Porcine Reproductive and Respiratory Syndrome (PRRS)-infected farm after sow vaccination with an attenuated PRRS vaccine. Vet. Microbiol., 111: 151-157. PMID: 16280205

Alvarez, E., A. Fernandez-Garcia, C. Prieto, J.J. Martinez-Lobo and I. Simarro et al., 2006. Efficacy of a Spanish modified live virus vaccine against homologous porcine reproductive and respiratory syndrome virus infection. Spanish J. Agric. Res., 4: 213-220.

Amonsin, A., R. Kedkovid, S. Puranaveja, P. Wongyanin and S. Suradhat et al., 2009. Comparative analysis of complete nucleotide sequence of Porcine Reproductive and Respiratory Syndrome Virus (PRRSV) isolates in Thailand (US and EU genotypes). Virol. J., 16: 6-143. DOI: 10.1186/1743422X-6-143

Balka, G., A. Hornyak, A. Balint, I. Kiss and S. Kecskemeti et al., 2008. Genetic diversity of porcine reproductive and respiratory syndrome virus strains circulating in Hungarian swine herds. Vet. Microbiol., 127: 128-135. PMID: 17869032

Bassaganya-Riera, J., B.J. Thacker, S. Yu, E. Strait and M.J. Wannemuehler et al., 2004. Impact of immunizations with porcine reproductive and respiratory syndrome virus on lymphoproliferative recall responses of CD8+ T cells. Viral Immunol., 17: 25-37. PMID: 15018660 
Beilage, E.G., H. Nathues, D. Meemken, T.C. Harder and M.G. Doherr et al., 2009. Frequency of PRRS live vaccine virus (European and North American genotype) in vaccinated and non-vaccinated pigs submitted for respiratory tract diagnostics in NorthWestern Germany. Prev. Vet. Med., 92: 31-37. DOI: 10.1016/j.prevetmed.2009.07.010

Botner, A., B. Strandbygaard, K.J. Sorensen, P. Have and K.G. Madsen et al., 1997. Appearance of acute PRRS-like symptoms in sow herds after vaccination with a modified live PRRS vaccine. Vet. Rec., 141: 497-499. PMID: 9402722

Cano, J.P., S.A. Dee, M.P. Murtaugh and C. Pijoan, 2007a. Impact of a modified-live porcine reproductive and respiratory syndrome virus vaccine intervention on a population of pigs infected with a heterologous isolate. Vaccine, 25: 4382-4391. PMID: 17451850

Cano, J.P., S.A. Dee, M.P. Murtaugh, C.A. Trincado and C. Pijoan, 2007b. Effect of vaccination with a modified-live porcine reproductive and respiratory syndrome virus vaccine on dynamics of homologous viral infection in pigs. Am. J. Vet. Res., 68: 565571. PMID: 17472459

Cho, J.G. and S.A. Dee, 2006. Porcine reproductive and respiratory syndrome virus. Theriogenology, 66: 655662. DOI: 10.1016/j.theriogenology.2006.04.024

Chung, W.B., M.W. Lin, W.F. Chang, M. Hsu and P.C. Yang, 1997. Persistence of porcine reproductive and respiratory syndrome virus in intensive farrow-tofinish pig herds. Can. J. Vet. Res., 61: 292-298. PMID: 9342454

Darwich, L., I. Diaz and E. Mateu, 2010. Certainties, doubts and hypotheses in porcine reproductive and respiratory syndrome virus immunobiology. Virus Res., 154: 123-132. PMID: 20659507

Dewey, C., G. Charbonneau, S. Carman, A. Hamel and G. Nayar et al., 2000. Lelystad-like strain of Porcine Reproductive and Respiratory Syndrome Virus (PRRSV) identified in Canadian swine. Can. Vet. J., 41: 493-494. PMID: 10857036

Dewey, C.E., S. Wilson, P. Buck and J.K. Leyenaar, 1999. The reproductive performance of sows after PRRS vaccination depends on stage gestation. Prev. Vet. Med., 40: 233-241. PMID: 10423777

Dotti, S., R. Villa, E. Sossi, G. Guadagnini and F. Salvini et al., 2011. Comparative evaluation of PRRS virusinfection in vaccinated and naivepigs. Res. Vet. Sci., 90: 218-25. DOI: 10.1016/j.rvsc.2010.06.011
Drexler, C.S., M.H. Witvliet, M. Raes, M.V.D. Laar and A.A. Eggen et al., 2010. Efficacy of combined porcine reproductive and respiratory syndrome virus and Mycoplasma hyopneumoniae vaccination in piglets. Vet. Rec., 166: 70-74. PMID: 20081177

Fang, Y., P. Schneider, W.P. Zhang, K.S. Faaberg and E.A. Nelson et al., 2007. Diversity and evolution of a newly emerged North American Type 1 porcine arterivirus: Analysis of isolates collected between 1999 and 2004. Arch. Virol., 152: 1009-1017. PMID: 17323198

Forsberg, R., T. Storgaard, H.S. Nielsen, M.B. Oleksiewicz and P. Cordioli et al., 2002. The genetic diversity of European type PRRSV is similar to that of the North American type but is geographically skewed within Europe. Virology, 299: 38-47. PMID: 12167339

Gimeno, M., I. Diaz, L. Darwich, E. Mateu and A. Callen et al., 2010. Comparison of immune response between PRRS vaccination using PROGRESSIS $®$ an inactivated vaccine or a combination of inactivated and a modified live vaccine. Proceedings of the 21st International Pig Veterinary Society Congress, Jul. 18-21, Vancouver, Canada, pp: 27.

Goldberg, T.L., E.C. Hahn, R.M. Weigel and G. Scherba, 2000. Genetic, geographical and temporal variation of porcine reproductive and respiratory syndrome virus in Illinois. J. Gen. Virol., 81: 171179. PMID: 10640555

Indik, S., L. Valicek, D. Klein and J. Klanova, 2000. Variations in the major envelope glycoprotein GP5 of Czech strains of porcine reproductive and respiratory syndrome virus. J. Gen. Virol., 81: $2497-$ 2502. PMID: 10993939

Joisel, F., G. Reynaud, C. Charreyre and J.B. Herin, 2001. PRRS: Vaccination with a killed vaccine, field experience. PIG J., 48: 120-137.

Kapur, V., M.R. Elam, T.M. Pawlovich and M.P. Murtaugh, 1996. Genetic variation in porcine reproductive and respiratory syndrome virus isolates in the midwestern United States. J. Gen. Virol., 77: 1271-1276. DOI: 10.1099/0022-1317-77

Keffaber, K.K., 1989. Reproductive failure of unknown etiology. Am. Assoc. Swine Pract. Newsl., 1: 1-10.

Key, K.F., G Haqshenas, D.K. Guenette, S.L. Swenson and T.E. Toth et al., 2001. Genetic variation and phylogenetic analyses of the ORF5 gene of acute porcine reproductive and respiratory syndrome virus isolates. Vet. Microbiol., 83: 249-263. PMID: 11574173 
Kim, H., H.K. Kim, J.H. Jung, Y.J. Choi and J. Kim et al., 2011. The assessment of efficacy of porcine reproductive respiratory syndrome virus inactivated vaccine based on the viral quantity and inactivation methods. Virol. J., 8: 323-327. PMID: 21703032

Kimman, T.G., L.A Cornelissen, R.J. Moormann, J.M.J. Rebel and N. Stockhofe-Zurwieden, 2009. Challenges for Porcine Reproductive and Respiratory Syndrome Virus (PRRSV) vaccinology. Vaccine, 27: 37043718. PMID: 19464553

Kritas, K., C. Alexopoulos, C.S. Kyriakis, E. Tzika and S.C. Kyriakis, 2007. Performance of fattening pigs in a farm infected with both Porcine Reproductive and Respiratory Syndrome (PRRS) virus and porcine circovirus type 2 following sow and piglet vaccination with an attenuated PRRS vaccine. J. Vet. Med. Physiol. Pathol. Clin. Med., 54: 287-291. PMID: 17650147

Labarque, G., K.V. Reeth, H. Nauwynck, C. Drexler and S. Van Gucht et al., 2004. Impact of genetic diversity of European-type porcine reproductive and respiratory syndrome virus strains on vaccine efficacy. Vaccine, 22: 4183-4190. PMID: 15474708

Labarque, G., S. Van Gucht, K. Van Reeth, H. Nauwynck and M. Pensaert, 2003. Respiratory tract protection upon challenge of pigs vaccinated with attenuated porcine reproductive and respiratory syndrome virus vaccines. Vet. Microbiol., 95: 187197. PMID: 12935746

Martelli, P., P. Cordioli, L.G. Alborali, S. Gozio and E.D. Angelis et al., 2007. Protection and immune response in pigs intradermally vaccinated against Porcine Reproductive and Respiratory Syndrome (PRRS) and subsequently exposed to a heterologous European (Italian cluster) field strain. Vaccine, 25: 3400-3408. PMID: 17276558

Martelli, P., S. Gozio, L. Ferrari, S. Rosina and E. De Angelis et al., 2009. Efficacy of a modified live Porcine Reproductive and Respiratory Syndrome Virus (PRRSV) vaccine in pigs naturally exposed to a heterologous European (Italian cluster) field strain: Clinical protection and cell-mediated immunity. Vaccine, 27: 3788-3799. PMID: 19442420

Mateu, E. and I. Diaz, 2008. The challenge of PRRS immunology. Vet. J., 177: 345-351. PMID: 17644436

Mateu, E., I. Diaz, L. Darwich, J. Casal and M. Martin et al., 2006. Evolution of ORF5 of Spanish porcine reproductive and respiratory syndrome virus strains from 1991 to 2005. Virus Res., 115: 198-206. PMID: 16269197
Meier, W.A., J. Galeota, F.A. Osorio, R.J. Husmann and W.M. Schnitzlein et al., 2003. Gradual development of the interferon-gamma response of swine to porcine reproductive and respiratory syndrome virus infection or vaccination. Virology, 309: 18-31. PMID: 12726723

Meulenberg, J.J., M.M. Hulst, E.J.D. Meijer, P.L. Moonen and A.D. Besten et al., 1993. Lelystad virus, the causative agent of Porcine Epidemic Abortion and Respiratory Syndrome (PEARS), is related to LDV and EAV. Virology, 192: 62-72. PMID: 8517032

Misinzo, G., P.L. Delputte, P. Meerts, C. Drexler and H.J. Nauwynck, 2006. Efficacy of an inactivated PRRSV vaccine: induction of virus-neutralizing antibodies and partial virological protection upon challenge. Adv. Exp. Med. Biol., 581: 449-454. PMID: 17037577

Murtaugh, M.P., M.R. Elam and L.T. Kakach, 1995. Comparison of the structural protein coding sequences of the VR-2332 and Lelystad virus strains of the PRRS virus. Arch. Virol., 140: 1451-1460. PMID: 7661696

Murtaugh, M.P., T. Stadejek, J.E. Abrahante, T.T. Lam and F.C. Leung, 2010. The ever-expanding diversity of porcine reproductive and respiratory syndrome virus. Virus Res., 154: 18-30. PMID: 20801173

Nelsen, C., M.P. Murtaugh and K.S. Faaberg, 1999. Porcine reproductive and respiratory syndrome virus comparison: Divergent evolution on two continents. J. Virol., 73: 270-280. PMID: 9847330

Neumann, E.J., J.B. Kliebenstein, C.D. Johnson, J.W. Mabry and E.J. Bush et al., 2005. Assessment of the economic impact of porcine reproductive and respiratory syndrome on swine production in the United States. J. Am. Vet. Med. Assoc., 227: $385-$ 392. PMID: 16121604

Nilubol, D., K.B. Platt, P.G. Halbur, M. Torremorell and D.L. Harris, 2004. The effect of a killed Porcine Reproductive and Respiratory Syndrome Virus (PRRSV) vaccine treatment on virus shedding in previously PRRSV infected pigs. Vet. Microbiol., 102: 11-18. PMID: 15288922

Oleksiewicz, M.B., A. Botner, P. Toft, T. Grubbe and J. Nielsen et al., 2000. Emergence of porcine reproductive and respiratory syndrome virus deletion mutants: Correlation with the porcine antibody response to a hypervariable site in the ORF 3 structural glycoprotein. Virology, 267: 135-140. PMID: 10662609 
Papatsiros, V.G., 2012a. Impact of a killed PRRSV vaccine on sow longevity in a PRRSV infected swine herd. J. Applied Anim. Res. DOI: 10.1080/09712119.2012.692323

Papatsiros, V.G., 2012b. Porcine herd health management practices for the control of PRRSV Infection. In: A Bird's-Eye View of Veterinary Medicine, Perez-Marin, C.C., (Ed.)., InTech. www.amazon.com/Birds-Eye-View-VeterinaryMedicine-ebook/dp/B008LQTERA

Papatsiros, V.G., C. Alexopoulos, C. Boscos and S.C. Kyriakis, 2011. Impact of a porcine reproductive and respiratory syndrome inactivated vaccine on the health and semen traits of boars. J. Hellenic Vet. Med. Soc., 62: 221-228.

Papatsiros, V.G., C. Alexopoulos, S.K. Kritas, G. Koptopoulos and H.J. Nauwynck et al., 2006. Longterm administration of a commercial Porcine Reproductive and Respiratory Syndrome Virus (PRRSV)-inactivated vaccine in PRRSVendemically infected sows. J. Vet. Med. B Infect. Dis. Vet. Public Health, 53: 266-272. PMID: 16907957

Pejsak, Z. and I. Markowska-Daniel, 2006. Randomised, placebo-controlled trial of a live vaccine against porcine reproductive and respiratory syndrome virus in sows on infected farms. Vet. Rec., 158: 475-478. PMID: 16603552

Piras, F., S. Bollard, F. Laval, F. Joisel, G. Reynaud, C. Charreyre, C. Andreoni, V. Juillard, 2005. Porcine Reproductive and Respiratory Syndrome (PRRS) virus-specific interferon-gamma(+) T-cell responses after PRRS virus infection or vaccination with an inactivated PRRS vaccine. Viral Immunol., 18: 381389. PMID: 16035950

Plana-Duran, J., M. Bastons, A. Urniza, M. Vayreda and X. Vila et al., 1997. Efficacy of an inactivated vaccine for prevention of reproductive failureinduced by porcinere productive and respiratory syndrome virus. Vet. Microbiol., 55: 361-370. DOI: 10.1016/S0378-1135(96)01317-X

Prieto, C., E. Alvarez, F.J. Martinez-Lobo, I. Simarro and J.M. Castro, 2008. Similarity of European porcine reproductive and respiratory syndrome virus strains to vaccine strain is not necessarily predictive of the degree of protective immunity conferred. Vet. J., 175: 356-363. PMID: 17560818
Prieto, C., P. Suarez, I. Simarro, C. Garcia and A. Fernandez et al., 1997. Transplacental infection following exposure of gilts to porcine reproductive and respiratory syndrome virus at the onset of gestation. Vet. Microbiol., 57: 301-311. PMID: 9444067

Roitha, L.T., S. Hammonda, S.M. Todda, Y. Nia and T. Cecerea et al., 2011. A modified live PRRSV vaccine and the pathogenic parent strain induce regulatory $\mathrm{T}$ cells in pigs naturally infected with Mycoplasma hyopneumoniae. Vet. Immunol. Immunopath., 140: 312-316. PMID: 21272944

Ropp, S.L., C.E. Mahlum-Wees, Y. Fang, E.A. Nelson and K.D. Rossow et al., 2004. Characterization of emerging European-like porcine reproductive and respiratory syndrome virus isolates in the United States. J. Virol., 78: 3684-3703. DOI: 0.1128/ JVI.78.7.3684-3703.2004

Rowland, R.R., 2010. The interaction between PRRSV and the late gestation pig fetus. Virus Res., 154: 114-122. PMID: 20832434

Scortti, M., C. Prieto, E. Alvarez, I. Simarro and J.M. Castro, 2007. Failure of an inactivated vaccine against porcine reproductive, respiratory syndrome to protect gilts against a heterologous challenge with PRRSV. Vet. Res., 161: 809-813. PMID: 18083979

Scortti, M., C. Prieto, I. Simarro and J.M. Castro, 2006. Reproductive performance of gilts following vaccination and subsequent heterologous challenge with European strains of porcine reproductive and respiratory syndrome virus. Theriogenology, 66: 1884-1893. PMID: 16806451

Shi, M., T.T. Lam, C.C. Hon, R.K. Hui and K.S. Faaberg et al., 2010a. Molecular epidemiology of PRRSV: A phylogenetic perspective. Virus Res., 154: 7-17. PMID: 20837072

Shi, M., T.T. Lam, C.C. Hon, M.P. Murtaugh and P.R. Davies et al., 2010b. Phylogeny-based evolutionary, demographical and geographical dissection of North American type 2 porcine reproductive and respiratory syndrome viruses. J. Virol., 84: 87008711. PMID: 20554771

Stadejek, T., A. Stankevicius, T. Storgaard, M.B. Oleksiewicz and S. Belak et al., 2002. Identification of radically different variants of porcine reproductive and respiratory syndrome virus in Eastern Europe: towards a common ancestor for European and American viruses. J. Gen. Virol., 83: 1861-1873. PMID: 12124450 
Stadejek, T., M. Porowski and Z. Pejsak, 2005. Viraemia and seroconversion in piglets following vaccination with PRRSV-EU type vaccine-a field observation. Bull. Vet. Inst. Pulawy, 49: 273-277.

Stadejek, T., M.B. Oleksiewicz, A.V. Scherbakov, A.M. Timina and J.S. Krabbe et al., 2008. Definition of subtypes in the European genotype of porcine reproductive and respiratory syndrome virus: Nucleocapsid characteristics and geographical distribution in Europe. Arch. Virol., 153: 14791488. PMID: 18592131

Stadejek, T., M.B. Oleksiewicz, D. Potapchuk and K. Podgorska, 2006. Porcine reproductive and respiratory syndrome virus strains of exceptional diversity in Eastern Europe support the definition of new genetic subtypes. J. Gen. Virol., 87: 1835-1841. PMID: 16760385

Thacker, E.L., B.J. Thacker, T.F. Young and P.G. Halbur, 2000. Effect of vaccination on the potentiation of Porcine Reproductive and Respiratory Syndrome Virus (PRRSV)-induced pneumonia by Mycoplasma hyopneumoniae. Vaccine, 18: 1244-1252. PMID: 10649626

Thanawongnuwech, R. and S. Suradhat, 2010. Taming PRRSV: Revisiting the control strategies and vaccine design. Virus Res., 154: 133-140. PMID: 20851723

Toplak, I., D. Rihtarica, P. Hostnika, J. Groma and M. Stukeljb et al., 2012. Identification of a genetically diverse sequence of porcine reproductive and respiratory syndrome virus in Slovenia and the impact on the sensitivity of four molecular tests. J. Virol. Methods, 179: 51-56. PMID: 22001545
Vanhee, M., P.L. Delputte, I. Delrue, M.F. Geldhof and H.J. Nauwynck, 2009. Development of an experimental inactivated PRRSV vaccine that induces virus-neutralizing antibodies. Vet. Res., 40: 63. PMID: 19674539

Wensvoort, G., C. Terpstra, J.M.A. Pol, E.A. Laak and M. Bloemraad et al., 1991. Mystery swine disease in the Netherlands: The isolation of Lelystad virus. Vet. Q., 13: 121-130. PMID: 1835211

Zimmerman, J.J., D.A. Benfield, M.P. Murtaugh, F.A. Osorio and G.W. Stevenson et al., 2006. Porcine Reproductive and Respiratory Syndrome Virus (Porcine Arterivirus). In: Diseases of Swin, Straw, B.E., J.J. Zimmerman, S.D. Allaire and D.J. Taylor (Eds)., John Wiley and Sons, Oxford, ISBN-10: 081381703X, pp: 387-417.

Zuckermann, F.A., E.A. Garcia, I.D. Luque, J. Christopher-Hennings and A. Doster et al., 2007. Assessment of the efficacy of commercial Porcine Reproductive and Respiratory Syndrome Virus (PRRSV) vaccines based on measurement of serologic response, frequency of gamma-IFNproducing cells and virological parameters of protection upon challenge. Vet. Microbiol., 123: 6985. PMID: 17376612 